\author{
Article Type: Research Article \\ Year: 2019 \\ V/I: $5(1)$ \\ Pages: $11-28$ \\ Corresponding Author: Vali Ilie / brainstorming71@yahoo.com \\ DOI: http://dx.doi.org/10.19148/ijhbs.543980 \\ Citation Information: \\ Ilie, V. (2019). Study on adult learning motivation. The International Journal of Human and \\ Behavioral Science, 5(1), 11-28. doi: 10.19148/ijhbs.543980
}

Received: 24/03/2019

Accepted: 10/06/2019

Published: 26/06/2019

\title{
Study on Adult Learning Motivation
}

\author{
Vali Ilie, Department of Teacher Training, University of Craiova,
} ORCID: https://orcid.org/ 0000-0002-5354-4787

\begin{abstract}
There are several theories and models that explain adult learning. In adulthood, people are self-directed, they resort to experiential and transformative learning. Influenced by a number of bio-psycho-socio-cultural aspects, adult learning is based on strong motivation. In recent decades, there have been explored various reasons that stimulate people to engage in continuous learning or training activities. People have different purposes and interests, to which they give a less or greater importance. Some people are strongly motivated to have professional success, others are more interested in positive social contacts (the need for affiliation) or in interpersonal power (the need for power). Starting from these considerations, we developed a study on adult motivation. The adults included in the sample are trainees of the University of Craiova, enrolled in the psycho-pedagogic module, postgraduate. The proposed goal is to identify the reasons that are the basis of lifelong learning. We have assumed that there is a wide range of reasons that determine adults to learn, and that it is necessary to know them exactly when designing and unfolding the educational programs they are involved in. The research instrument we have used is the questionnaire and the results obtained from its application are the starting point in the discussions and conclusions of this study.
\end{abstract}

Keywords: education, andragogy, adulthood, needs

\section{Introduction}

The fast evolutions of societies and the alert pace of development and transformation of the world we live in justify the need for lifelong learning. Education does not end once the compulsory education is completed, but it is a permanent process that continues in adulthood. The field of knowledge and social practice whose specific object is the educational intervention for the benefit of the adults, andragogy describes adult education. Understood as the theory (the science of understanding) and practice (support) specific to adult education, it emerged as a necessity driven by the great imbalances between the individual and the society produced in the second half of the 20th century. The first International Conference on Adult Education took place in Elsinore in 1949 when the world community felt the need to lean on "moral reconstruction", to restore peace and harmony between different cultures and nations, to restore confidence in humanity. In Elsinore, for the first time, in a clear manner adopted by all participants, the objectives of adult education in the new world after the war, were defined. After 1950, many international and national adult education institutions (eg the European Center for Leisure and Education, Institut National pour la Formation des Adultes) have been established, magazines, brochures and books were published (eg the review "Education Permanente"), various scientific meetings were held 
(eg the International Conference on Adult Education in Tokyo, 1972, the International Conference in Paris, 1985).

The need to promote adult education and lifelong learning emerged some time ago, but in recent decades, increased efforts have been made to stimulate participation in a solid society and in an economy based on knowledge. The first adult high school is considered the one organized by Grundtvig in Denmark. It established a Scandinavian model of adult education (community education, focusing on solving the socio-economic problems of the region). Today, the Grundtvig Program is one of the EU's Programs and it is specific to adult education. It is mainly open to all types of institutions and organizations that work with the adult education system and addresses in particular: Organizations dealing with the education of adults; associations and regional, national European providers of this type of adult education. In 1973, the OECD published the report entitled "Recurrent Education: A Strategy for Lifelong Learning", highlighting the relationship between recurrent education and lifelong learning, as an interaction between work and education. If The Organization for Economic Co-operation and Development (OECD) is based on an economic paradigm, UNESCO is closer to intellectual and moral paradigms (OECD, 1973). In 1976, at the UNESCO General Conference, adult education was defined as a set of organized educational processes, extending initial education. The aim was to promote and enhance adult education (Objective 5.6.) through the following themes: "The contribution to the development of policies and the establishment and strengthening of national institutions, services and machinery for a concerted action and cooperation in the field of adult education"; "Development of documentation and improvement of the flow of information in the field of adult education"; "Improvement of methods and techniques, training activities and preparation of materials suited to the special features of adult learning"; "Sub regional, regional and international cooperation between adult education bodies" (UNESCO, 1979).

The European Commission emphasizes the importance of adult education through the expression lifelong learning. The European Commission defines lifelong learning as: "All learning activity undertaken throughout life, with the aim of improving knowledge, skills and competences within a personal, civic, social and/ or employment-related perspective" (European Commission, 2001, p. 9). The motivation and stimulation of adults is not only a problem of self-determination, but also one of educational policy (the public education system offers a wide range of services courses, programs - and is supported by coherent policies at European level). The Communication of the Commission on Learning among adults in 2006 entitled "It's never too late to learn" emphasizes the importance of adult learning as a key element of continuous learning. According to the 2006 Recommendation of the European Parliament and the European Council "Key Competences for Lifelong Learning 2006/962/EC", the competence of "learning to learn" is the ability to engage and persevere in learning, to organize their own learning by effectively managing time and information, both individually and in groups. This includes the awareness of the process and of the individual learning needs, the identification of the existing opportunities and the ability to overcome the obstacles that may arise in order to achieve successful learning.

Lifelong education is viewed more as a personal duty, as an individual long-term task. However, this is an educational project which combines the individual dimension with the social dimension of education. Adult education encompasses educational processes that: Continue initial education; replace or compensate for initial education; contribute to continuing vocational training; provide basic/ minimum education for people changing their profession. This way we find that adult learning includes all forms of learning attended by adults after completing their studies and initial training. The satisfaction of the need for competence is valid all your life; it begins to affirm in adolescence and develops in adulthood. It is observed that "a vast number of studies have demonstrated the importance of ongoing feelings of competence for optimal functioning and wellbeing" (Kocayörük, 2010, p. 723). 
For adults, the learning process is a process of evolution that originates and activates inside the learner and develops at the same time with the individual's need to interact with the environment. The fluctuating value scale, the fear of the unknown, but also the low self-esteem, the distrust of the personal potential, may be the causes of giving up the idea of education. The option to participate or not in continuous training activities is related to the value that adults give to these activities. The cost-benefit ratio should not be neglected, but there are several subjective and objective reasons that lead to engaging in continuous training, professional reconversion, etc. In such situations, the motivational factor has an essential role, especially if it is developed based on self-knowledge and the identification of the main obstacles of development. The channeling of motivation towards the transformation/ development process is an important aspect, and the identification of the reasons for adult learning is a starting point in designing and implementing educational programs.

\subsection{Adulthood - theories, models}

The moment of becoming an adult has become more ambiguous lately, less uniform, but, nevertheless we find out that it is progressing in a gradual and complex way. Education and training are now more valuable than before, because jobs are less permanent, career paths have become more fluid and the awareness of the link between economy and education has increased. Adulthood has traditionally been defined by combining criteria such as age and setting certain social reference points. Most countries have a legally defined age to determine when a person is considered an adult (full age). Age influences everyday social interactions and is often related to personality attributes and behavioral moods, but also to a certain conception of oneself, about the world and about life. Marrying and setting up a family, practicing a profession or practicing a craft are key moments that transform and crystallize adult identities. Our identities, the roles we play as adults, what we want to learn and the ways we prefer to learn are traced by to culture and the society we live in.

There are different types of adults: Young adults, becoming adults, and old adults (by age); systematically and non-systemically educated adults (by the systematization of training); working adults and adults who are not employed (by the degree of professional involvement). The existence of several types of adults generates a series of differences. For example, the learning ability of young adults is superior to that of older adults as well as their ability to organize new information about their content or meaning. Older adults, on the other hand, are equal or superior to young adults in their ability to keep their general information and in their accumulated cultural knowledge.

The term andragogy was first used in 1833 by the German professor A. Kapp. In the 1920s, adult education became a theoretical field, describing sets of explicit reflections on "what, what for and how to teach them to adults". Strongly influenced by J. Dewey's educational philosophy, E.C. Lindeman was the first to set the foundations of a systematic theory of adult learning by identifying the characteristics of adult learners. Later, M. Knowles's concept of andragogy ("The art and science of helping adults to learn") was built on two defining attributes: The students' concept of learning (as being self-directed and autonomous) and the concept of the teacher's role as a facilitator of learning.

There have been few theories about adulthood. A point of reference remains the theory of E. Erikson, who described a sequence of psychosocial stages that he considers applicable to individuals from different cultures and societies. In his work "Childhood and Society" (1950), the author brings three major contributions to the study of the individual (Sillamy, 1996, p. 118): "First of all, he claims that the development of the individual takes place from the beginning to the end of his existence; he, then, shows that in addition to the psycho-sexual stages described by Freud, there are psychosocial stages during which the individual establishes new orientations, important for himself and his social world; finally, he claims that each stage has both a positive 
component and a negative component, the "choice" being made under the influence of social interaction (the interaction of the individual with himself and his environment)".

M. Knowles's andragogic model (in antithesis with the pedagogical one) is a procedural one, which means it wants to provide procedures and resources to help learners get information and skills. It refers to how adults learn and describes a theory of adult learning. The author proposes the following hypotheses: Adults are self-directed learners; adult learners bring their rich experience to the educational setting; adults enter the educational settings ready to learn; adults are problem-centered in their learning. Other two suppositions appear in later publications: Adults are mostly driven by internal motivation rather than external motivators; adults need to know the reason for learning something (Knowles et al., 1984). The andragogy principles formulated by Knowles have had an impact on the hierarchical motivational theory of human needs. They relate to: Intrinsic motivation to learn, readiness to learn, previous learning, self-directed learning, the need to know. If we make an analogy with Maslow's proposed hierarchy of needs, we can observe that the need for self-esteem and self-updating play an important role in the progress of adult learners.

Behavioral intentions were considered to be the best predictor of behavior (Fishbein \& Ajzen, 1975). Fishbein and Ajzen developed the Theory of Reasoned Action. The authors described two basic factors underlying this model: The attitude towards behavior (an attitude is formed on the basis of behavioral ideas that generate preference or rejection of behavior itself) and the social norm (it refers to the pressure exerted by the immediate circumstances of a person). The Theory of Planned Behavior took the components of the Theory of Reasoned Action, but added perceived behavioral control as an additional factor predicting both behavioral intentions and behavior.

The Expectancy Valence Model of K. Rubenson (1977) starts from the interaction between the individual and his environment. The model includes personal variables (the individual's previous experience, "congenital properties" - personal attributes, and current needs - developmental tasks confronted during the life cycle) and environmental variables (the degree of "hierarchical structure" of an individual's life space - environmental constraints on one's control over one's situation, norms and values of the individuals and their reference groups, and available "study possibilities" - institutional facilitators or deterrents to continuing education). The influence of these variables is mediated by the individual's response to their meaning. The original element of this model is that what makes the difference is how the individual perceives these variables. This helps us to explain why individuals in seemingly similar circumstances respond differently to the educational opportunities offered. The valency in the model refers to the value that an individual attach to the participation, and the expectancy refers to specific hopes with regard to successful participation in an educational activity.

Proficiency theory of adult learning (Knox, 1977) uses competence as a unifying concept to link the acquisition of knowledge, skills and attitudes to the improved performance, an aspect that greatly motivates adult learning. The essence of this theory is at the center of the discrepancy between the current and the desired level of competence. Many personality-related characteristics, such as values, interest and self-image, hopes and expectations, affect the person's effort to enhance competencies. A. Knox stresses that "active interest and participation are more likely when the learner helps to identify objectives, selects learning tasks and understands procedures" (Knox, 1977, p. 411).

The transformative learning theory is based on the belief that learning takes place when the new sense is shared with a previous experience or an old sense is reinterpreted and seen in a new light. Unlike the andragogic model, transformative learning focuses on the cognitive process of forming meaning, aiming at a fundamental change in the way we look at the world. By examining the current beliefs, the learner is heading towards exploring new ways to deal with the dilemma that 
can lead to the change of a belief, attitude, or an entire perspective. Mezirov (1978a; 1978b)) promotes a process of transformation that leads the learner from a moment of disorientation to a moment of transformative self-reflection that results in change. The ten phases of transformative learning are: Phase 1 (a disorienting dilemma); phase 2 (a self-examination with feelings of guilt or shame); phase 3 (a critical assessment of epistemic, sociocultural, or psychic assumptions); phase 4 (recognition that one's discontent and the process of transformation are shared and that others have negotiated a similar change); phase 5 (exploration of options for new roles, relationships, and actions); phase 6 (planning a course of action); phase 7 (acquisition of knowledge and skills for implementing one's plans); phase 8 (provisional testing of new roles); phase 9 (building of competence and self-confidence in new roles and relationships); phase 10 (a reintegration into one's life on the basis of conditions dictated by one's perspective).

Cross (1981) introduced two conceptual frameworks to describe various aspects of adult learning and to stimulate related research. With the first of these she dubbed the COR (Chain-of-Response) model. The Chain of Response Model of the Cross (1981) represents a cycle of decision-making processes an individual experience. Two classes of variables are identified: Personal characteristics (physical, psychological and socio-cultural dimensions) and situational characteristics (time, location, etc.). The starting point of this model is the learning-oriented person (self-perception). If the person is not motivated to participate in his/ her education, it is very unlikely that he/ she will get involved, no matter how much he/ she is doing to remove external barriers. This is related to attitudes towards education. The next step is related to the expectations and values associated with the participation (the decision to participate). The final steps consist of: Balancing opportunities and obstacles, access to information and the real decision to participate or not to participation.

The author named the second model according to the characteristics of the adult learners: Characteristics of Adults as Learners (CAL): "I offer the following model as a tentative framework to accommodate current knowledge of what we know about adults as learners, in the hope that it may suggest ideas for further research and for implementation" (Cross, 1981, p. 234). Her aim was to describe some differences between adults and children, so alternative teaching strategies could be developed.

According to Darkenwald and Merriam (1982), Knowles' andragogic theory hypotheses start from self-development, which is at the heart of adult learning and development. They target five goals in adult education (Darkenwald \& Merriam, 1982):

1. Cultivating the intellect (achieving this goal is seen as a development of rationality through a curriculum that emphasizes liberal studies and a teacher-centered methodology through the transmission of valuable educational content).

2. Individual self-updating (more emphasis is placed on the individual than on the content, more on the affective than the cognitive; although they favor individual development, it is difficult to translate the ideal into practice - the teacher is a facilitator and the adult learner is at the core of learning experience).

3. Social-improvement (one of the functions of adult education is to train and develop creative individuals and not only to improve individuality or social consciousness; thus social life is protected and adult education is the one that creates better citizens and a society which offers the satisfaction of individual life).

4. Social transformation (a radical social change is supported by adult education; education is responsible for the values that an individual is asked to acquire).

5. Organizational effectiveness (to become more efficient in delivering goods and services, public and private organizations involve employees in various training, education and development courses). 
The psychosocial interaction model (PIS) emphasizes the social environment factors and the socio-economic status of the individual. Darkenwald and Merriam (1982) described the participatory behavior as being determined by a continuity of responses to internal stimuli (eg a self-fulfillment desire) and external stimuli (eg a life transition event). Thus, "adult education is not concerned with preparing people for life, but rather with helping people to live more successfully. Thus, if there is to be an overarching function of the adult education enterprise, it is to assist adults to increase competence, or to negotiate transitions, in their social roles (worker, parent, pensioner, etc.), to help them achieve greater fulfillment in their personal lives, and to assist them in solving personal and community problems" (Darkenwald \& Merriam, 1982, p. 9).

The experiential learning theory (ELT) is based on the idea that we are modeled by our experiences and that we learn best when we apply, when we put into practice. Theory focuses on those adaptive thinking modalities, from which productive and action thinking lines can be modeled. The experiential learning cycle proposed by Kolb (1984) is one of the most popular models and it integrates the experiential components of several influential theorists (eg J. Dewey, J. Piaget, K. Lewin). He showed that the learning styles are influenced by personality, educational specialization, career choice and the current working roles and tasks. According to Kolb (1984), human learning and personal development are synonymous processes involving the continuous integration of a distinct set of independent systems that give meaning to the circumstances of life. Kolb's experimental learning cycle is a four-stage process: Practical experience (the learners have active encounters during the activity); reflexive observation (the learners consciously reflect on experience); formation of abstract concepts (the learners are present and try to be aware of the model/ theory to be followed); testing in new situations: the learners try to test the planning of the model/ theory for their future experiences.

Most of these models emphasize the importance of exploiting the previous experience of the adults. Each model focuses on one aspect or another and neglects other significant aspects in adult education. Referring to certain limits does not make them less important; they contribute to the creation of an overall picture, each is a piece in a puzzle, and the way the authors combine the existing variables mark a conception or another, in time periods, different social structures and cultures. The lack of reference to cultural and economic aspects, the gap between theory and practice, the neglect of the diversity of the adult population, the incorrect estimation of implementation are some of the limits of these models and theories. With all these limits, the theories and models presented are attempts to explain learning in adults. Knowing the characteristics of adults, different models of their training can be designed, combining the psychosocial and pedagogical aspects.

\subsection{Characteristics of adults}

The concepts of "ages" or "phases" are used to broadly outline key periods in the human development calendar. Humans are complex beings and each stage of growth includes physical, cognitive, emotional and social developments. Taking into account the psychological development, the adult is a person whose self-concept is that of a mature person, demonstrating certain qualities and behaving in ways that are perceived as typical among adults in most cultures (Jarvis \& Wilson, 2002). From a biological point of view, adulthood generally begins when physical maturity is complete. From an ontogenetic perspective, the adult is the peak of evolution and development, followed by the involution period. From a legal point of view, adulthood associates with the freedom to sign a contract, to vote, to lead etc., considering that the adult is psychosocially developed. These aspects are attached to the cultural print, as cultures have different concepts and practices of exposing adults. From an educational perspective, the adult can still be subject to education and training processes.

Characteristics of adult learners are those components or attributes that typically describe adults in the position or state of learners. We can include here the needs they have when learning, the 
cognitive differences with young people, the self-concept, the need to know, the role of the previous experience, the orientation towards learning and the motivation for learning. Adults decide to participate in a learning process for specific reasons and because specific needs arise. They have different experiences that derive from a variety of situations, preferred learning styles, and other reasons compared to children and adolescents. Darkenwald and Merriam (1982) define an adult who learns as an individual whose predominant social role is determined by the adult status and who is involved in some organized and sustained learning activities in order to gain knowledge, attitudes or abilities. The behavior of a mature person is autonomous and motivated by conscious processes. G. Allport (1961) highlighted six adult-specific features: Extension of the sense of self; warm relation of the self to others; emotional security (self-acceptance); realistic perception, skills, and assignments; self-objectification - insight and humor; the unifying philosophy of life. Taking into account what constitutes a mature personality, he described the list as an ideal, recognizing that even the strongest of personalities have their foibles and their regressive moments; and to a large extent they depend on environmental support for their maturity (Allport, 1961).

From an educational point of view, adult education programs aimed at adult education should take into account that adults: Record higher learning outcomes compared to previous ages; valuates previous experience as a source of potentiation; associate professional knowledge with new elements introduced in the sphere of its own activity; want to know what to learn and why they have to learn something; solve real, immediate, practical-applicative problems; have performances that are well-shaped and focused on clear objectives; reflect the reflexive side in learning.

Starting from the theories and models presented above and referring to a number of other contributions, we can make a synthesis of the characteristics of adults (psychosocial development), which includes the following aspects (apud Knowles, 1970; Tough, 1971; Kidd, 1973; Urbańczyk, 1975; Knox, 1977; Brookfield, 1986; Hiemstra \& Sisco, 1990; Mezirow, 2000):

1. They have life experience (they are involved in family life, participate in community life, organize their free time activities and recreation, meaning is found through work and family life);

2. They have professional skills;

3. They have a learning style intensified in time;

4. They make rational choices as responsible social agents, free to act on them;

5. They are oriented towards a purpose (connected to real life, to the roles they play in the group, community, society);

6. They feel the need to validate the information received (they can establish some ideas on the basis of their experience and own conception);

7. They are practical (they expect what they learn to be useful at present and they are more receptive to the practical applications of knowledge);

8. They have control over planning learning;

9. They are oriented towards relevance (they must understand the reason for learning something, learning must have a practical application);

10. They turn to reflexive and transformative learning (it is generated especially when it comes to problems and tries to find ways to solve them);

11. They can be learning sources for both the instructor and colleagues to a great extent;

12. They are focused on working tasks;

13. They want the learning outcomes to be immediately applicable (they stop participating in education when they feel they are wasting their time);

14. They have the ability to think dialectically and contextually;

15. They have a greater ability to think in an abstract way (depending on the degree of practice in this direction); 
16. They participate actively (they learn well in a collaborative environment);

17. They can help with planning activities, together with their teachers or entertainers;

18. They are self-directed, autonomous and independent (they feel the need to be free to express themselves, the teacher plays the role of a facilitator of learning, ensuring the security of the learning environment);

19. Their attitude towards school tasks is more serious;

20. They do not always reveal the true reasons for participating in a continuous training activity;

21. They have a high degree of epistemic curiosity;

22. They memorize logically (emotionally active items occupy a place in memory for a longer period of time);

23. Imagination (closer to reality than in a child) is directed and highly creative, being subject to critical analysis;

24. The attention is greater and the role of voluntary attention is more important;

25 . They are rather intrinsically motivated to learn (eg professional satisfaction);

26. Emotions are closely related to building the sense of knowledge (emotions create memories);

27. They appreciate the friendliness of the trainer;

28. They feel the need to be respected (instructors must acknowledge their experience);

29. They have social responsibilities (they get involved civically, they are also interested in others, etc.) and they take responsibility for the decisions they make (they decide what is important to learn for them).

The parallel between children and adults brings to the fore a difference between the external processes that accompany teaching and learning (social difference, life experience, etc.). Adults learn in a more focused and selective manner, capitalizing on what they already know. When there is a foundation in socio-professional training, self-directed learning is the basis for transformational learning. There are, however, a series of situations when the adult learner has not completed his or her education or has not formed the skills needed to practice a profession, and this limits his possibilities and options. Developing basic skills (reading, writing, spoken language, numeracy skills and digital skills) through education can reduce social inequalities, fosters inclusion, cohesion and active citizenship and also contributes to improving the quality of life. Adult education is orientated towards concrete tasks. The desire to raise their level of training and to grow in their own eyes intensifies the tendency to form new skills. Although the strongest motivation is related to the possibilities to apply the accumulated knowledge directly, there are often a number of other reasons.

Benedict opposes two models of human growth (in Japan and in the US): While for the Japanese, the circle of life takes the form of a "U", with maximum freedom and indulgence at the two ends of life (childhood and old age) and a minimum of freedom in adulthood, for the Americans it looks like a "U" turned - the child and the old man are constrained and disciplined by the force of norms, while the adult is given the greatest freedom (Mahler, 1983).

For a better analysis of the subject, one must also keep in mind that the way adult age is understood has changed. Today, maturity is more subjective, more often related to a feeling than to an achievement, which means that external markers do not matter so much. Ideas about marriage and family have changed, investing in education no longer guarantees job security. Adulthood is a new stage of family life, which may be similar to a second honeymoon, or forces partners to realize that very few things connect them. Thus, we find that the old age scenario collapses, leaving room for uncertainty, insecurity and confusion. Paradoxically, with more opportunities to reinvent their own lives, adults sometimes experience a sense of insecurity or uselessness. That is why we consider the resorts as important, the reasons that push them to action, make them proactive and apply lifelong training. 


\subsection{The motivation of learning in adults}

The definitions of adult education are mostly focused on meeting the needs of individuals (to enrich their personal experience, to express their personality, to achieve their personal goals, to adapt to the world they live in, to make a personal effort to change). Starting from the distinction between education and learning, one can say that learning is related to experience: It changes due to experience (Harris \& Schwahn, 1961), it is a change of behavior as a result of experience (Cronbach, 1963) (apud Knowles et al., 2012, p. 12). Knowles' hypothesis is that adult learners are motivated mostly by internal pressures than by external pressures. Factors such as better jobs, promotions and better salaries are less motivating for adult learners than the desire to increase professional fulfillment, self-esteem and the quality of life.

Interested in experience, D. Kolb understands learning as "the process through which knowledge is created by transforming experience" (Kolb, 1984, p. 41). However, although experience clearly serves as a basis for adult learning, there are also some aspects that influence negatively, that can prevent adults from learning: Remembering past learning experiences, specific roles (eg, the parent role), distrust in learning new things, searching education only in times of transition, lack of time, lack of money, etc. as there are the strength and tenacity of the learning reasons, the perseverance and patience in overcoming difficulties depends on the learner's attitude toward learning. We share the idea that "the term adult refers to a social status rather than a biological age, since in some countries in the world, adulthood is reached at younger biological ages than in others. This point demonstrates the importance of recognizing that learning does not occur in social isolation and that the emergence of different forms of learning may be the result of social and cultural pressures rather than biologic differences alone" (Jarvis, 1987, p. 11).

A basic form of human activity, learning, is the energetically sustained action of two essential components - purpose and reason. It is not enough for the purpose of an activity to be clear, correct and rigorously formulated to work effectively. If there is no stimulation and energy support to achieve the goal, the activity cannot be carried out. Even if the adult has well-developed intellectual instruments, if he is not determined by something to learn, he will not achieve the desired performance. The impulse to expansion and personal development felt by an adult is an easily observable reason when it comes to its involvement in the act of learning. The inner necessity that causes the adult to act, the reason is the mobile that triggers, energizes and guides the action. There are different types of reasons that trigger adult participation in continuous training and development courses. They do not act independently, but form within the personality structure true networks, configurations or constellations. They can be grouped as follows: Individual or social; direct or indirect; primary or secondary; lower or higher; minor or major; invariable or variable; selfish or altruistic. From a psychological point of view, the interaction of motives in complex life situations implies a series of actions from adults - of choice (keeping some and rejecting others), of cooperation (mutual support of reasons) and of conflict (lead to the emergence of tension states which, if intense and prolonged, have negative effects). Preventing or eliminating motivational conflicts can be done by ordering and spacing in time of fulfilling motives.

Along with reasons, other constitutive aspects (necessities, interests, beliefs, ideals, conception of the world and life) come into the structure of motivation. Realities that cannot be denied, the needs continue to exist throughout life, even if adults choose to ignore them, satisfy them or not. The needs reflect the biopsychosocial balance of man under the conditions of the external environment requests. Being interdependent, they find their utmost expression in the need for self-accomplishment, which occurs as more and more needs are met on the lower levels. 
Interests are selective, relatively stable, and active orientations toward certain areas of activity. Representing long-term preferences, these may be: General or personal; positive or negative; professional or extra-professional (related to spending free time); technical, artistic, scientific or sportive; durable or short-lived. Important are the creative interests which are characterized by the search for new, original projects. When a learner shows interest in a particular curriculum topic or discipline, he can learn beyond the required limits, experiencing great satisfactions and achieving good results. Interests depend on several variables (the level of instruction, the emotional factor, the professional activity, the social role, etc.).

Maturity is the age at which man better understands the meaning of life, contributes to the accomplishment of the purpose of life, and strengthens his model of life, seen as a guide that helps him to choose, make decisions, build in a certain area or plan of existence. These elements are part of the ideal of life without which the adult would not make sense.

A motivational cognitive-value formation of maximum generality, the conception of the world and life encompasses all opinions, ideas, theories about man, nature and society. Adults can have different types of concepts: Realistic or utopian; scientific or non-scientific; materialistic or idealistic; progressive or retrograde. If adults develop and maintain positive values about the activities they undertake (literacy, retraining or training), they will facilitate learning.

The problem of success depends on the intensity of the motivational impulse. For extrinsically motivated behaviors, the optimum level of adjustment depends on the value (size) and the nature of the reinforcement. To increase learning motivation, adults want to clarify their concrete needs, so they will know clearly how they can use the learning experiences they are about to be trained. J. R. Kidd explains that "one of the reasons adults continue to learn well (..) is that they concentrate their learning on the areas of experience in which their interests also lie. Thus their motivation is substantial and, as everyone knows, wanting to learn is the greatest aid to learning" (Kidd, 1973, p. 91).

Motivation is important not only because it apparently improves learning but also because it mediates learning. In the adult learning process, high positive motivation can play the role of a compensating factor, especially if a person has poor skills or insufficient knowledge. In conjunction with the status and roles of a person, with their own aspirations and values, "the motivation for a task will be proportional to the ability to respond to the needs of security (trusting), affiliation (feeling of belonging), feeling competent (sense of competence). Motivation is a constellation of motives in interaction; at a certain age, a certain category of reasons prevails, which determines the general profile of motivation as a whole. Thus, sometimes adults learn because they are interested in this type of activity, because it gives them satisfaction, and sometimes they learn because they have to, which will determine a certain motivational profile. Essentially, reasons always will be organized around a dominant motif, to which all others are subordinated.

Among the best-known contributions to the research of the human motivational universe there are A. H. Maslow's theory, known in the scientific community as the "Hierarchy of needs" The highest motivation (self-updating) can only be achieved if other needs are met (Maslow, 1970). People who have a high need for performance generally have the following characteristics: They are realistic; especially looking for medium difficulty tasks, to be safe for success; they accept themselves and they are tolerant; they have a sense of humor; clearly distinguishing the situations they can control and those they cannot control; have the ability to postpone the reward time; they need to know the results of their actions and how they were appreciated; they are very creative they are concerned about the good of humanity. 
D. C. McClelland, one of H. A. Murray's disciples (the author of the TAT projective test) argues that three are the fundamental motives of human behavior, namely, the need to achieve (performance, success), the need for appurtenance (affiliation) and the need for power (authority, domination) . (...) The data obtained by McClelland showed that women are less motivated by the need for accomplishment than men. To explain this trend, M. Horner introduced the concept of "fear of success", arguing that women tend to avoid success, as society does not value positively (based on gender stereotypes) female success (apud Sălăvăstru, 2004, pp. 72-73).

In the process of changing reasons, changing the perspectives over time is also important. In fact, "an essential factor that determines the changing of reasons in relation to age is, on one hand, the diversity of the social situation and the physiological state of the human body at different times of his life and, on the other hand, the degree of satisfaction or frustration of the basic aspirations of man. (...) To the same extent, changing the conditions in which a person lives can suddenly produce the awakening of a numb need" (Urbańczyk, 1975, p. 81). Although increasing performance is not always in direct relation to the intensity of motivation, the aspirations and career motivation contribute to increasing learning efficiency. Career aspirations are a reflection of early preferences and tastes for work, school, and family roles, which in turn affect the routes to different types of jobs and career paths (Becker, 1993).

Adults intentionally engage in learning situations to reach a goal, to achieve their competence. J. R. Wlodkowski believes that the motivation is large and intrinsic in these individuals and that there must be four environmental conditions for adults to be motivated to learn (Wlodkowski, 1989): Establishing inclusion (creating a learning environment in which adults feel capable, respected, accepted and connected to one another); developing attitudes (creating a favorable provision for the learning experience and personal choice); improving meaning (creating challenging learning experiences that include student values and perspectives, past experiences, emotions, etc.); learning competency (creating situations in which adult learners are self-directed, responsible for their own lives, they are pragmatic and want to learn something relevant and meaningful, significant for their present lives or immediate future). These four conditions are used as rules for selecting training strategies and learning activities. If any of these four conditions is missing, adults are less likely to get involved in the learning process.

Self-Determination Theory (SDT) is a macro theory of motivation and human personality developed on the basis of E. L. Deci's and R. M. Ryan's research on motivation in the 1970s and 1980s. It takes into account the growth trends and the fundamental psychological needs to explain motivation and well-being. To update their potential, people need care from the social environment. In order to reach happiness and welfare, people must be encouraged by the social environment. If this does not happen and the basic needs are not met, there will be negative consequences. As it is claimed that autonomy, competence and connectivity are "innate psychological needs" (Ryan \& Deci, 2000, p. 70), theory is relevant in the context of adult education. It is suggested that extrinsic motivation (doing things for externally controlled reasons - "must") can be influenced by an autonomous motivation (doing things for freely chosen reasons - "I like") through an "internalization" and "integration". Theory identifies three needs (competence, relationship and autonomy) and claims that these needs are universal, but that their manifestation may be different due to different conditions of internalization. When intrinsically motivated, people engage in activities simply because they will feel good during their performance. On the other hand, extrinsic motivation implies the existence of instrumental motives. For example, an adult who has a hobby because he enjoys it manifests his selfdetermination, while the adult who takes on a new hobby because it looks impressive or captures the attention of others is not self-determined. 
The theory of self-determination consists of a series of sub-theories that have been developed to explain the motivational phenomena:

1. Cognitive Evaluation Theory: explains the effects of external influences on internal motivation and the way intrinsic motivation is affected by these external forces.

2. Organismic Integration Theory: is based on two essential ideas (behavior is regulated, in part, by internal structures that are developed through experience; human beings are active by their very nature).

3. Causality Orientations: describes the individual differences in how people move towards the environment and regulate behavior.

4. Basic Psychological: shows that psychological well-being and optimal functioning are based on autonomy, competence and relationship (essentially, this is the basis for the theory of selfdetermination).

5. Goal Contents Theory: describes the difference between the intrinsic goals (eg appreciation, self-realization) and external (eg financial success, fame) and their impact on human motivation and well-being.

6. Relations Motivation Theory: focuses on all possible human relationships and interactions that are essential for behavior, adaptation and well-being.

There is a great interest in the motivational factors of adult learning (eg Cross, 1981; Darkenwald \& Merriam, 1982; Houle, 1961; Merriam \& Caffarella, 1991). Adult motivational sources include: social relationships, social expectations, social welfare, professional achievement, refuge or relaxation, cognitive interest. A determined individual is someone who: Puts the intrinsic motivation first; is autonomous and enjoys the exercise of freedom; tries to have control over their activities; assumes responsibility for their own behavior; is guided by principles and relate to authentic values. When the individual looks at his past life, he evaluates whether his remaining life is satisfactory, whether he / she looks at his / her project and continues his / her goals and whether or not his / her project is positive or not. With this assessment, development, direction and self-realization of happiness confirmation interest (Kocayörük, Altıntaş, Șimşek, Bozanoğlu, \& Çelik, 2018).

In the 1960s, C. Houle designed a study to find out why grown-ups engaged in lifelong learning (some people are focusing on goals, using education as a means of accomplishment, another category of people is focused on activity, participate in learning by enjoying social contact, other people participate in learning for their own good and see life as a learning adventure). R. Boshier and J. B. Collins tested the truth of Houle's typology, noting that although the objectives pursued in learning were clear, initial orientations on behavior and learning were much more complex. Following a survey on subjects from different countries, they identified six motivational factors: social contact; social stimulation; professional advancement; community service; external expectations; cognitive interest (Boshier \& Collins, 1985).

There is more and more talking about the role of e-motivation: "Respondents used social network sites and texts to motivate themselves, and each other, to continue studying. I call this innovative application of technology e-motivation. Students used communication technology to transform their attitude, to change from wanting to leave to being motivated to stay" (Price \& Kadi-Hanifi, 2011). Motivation has not only an energizing or activating character on adult behavior but also one that directs behaviors. Thus, we can conclude that the motivation has two important segments - one of energizing, and the other of vectorization, of heading behavior towards a certain purpose.

\section{Methods}

The research is an observational one and took place during the academic year 2018-2019 at the University of Craiova. We used the questionnaire method because we consider it the most suitable to achieve the goal of the research. To ensure the internal validity, we controlled the external variables, knowing that motivation is influenced by various factors (eg the level of the previous 
experience, the age of the subjects, attachment to the values of the organization, conscientiousness, etc.). We also ensured the external validity of the research on identifying the main reasons that lead adults to learn, they always being able to extend the findings of the research to other types of learners and other types of organizations. In order to ensure the validity of the study results, we were careful that the procedure was reliable. In order to ensure the reliability of the data collection procedure, we set the main construct - the reasons for adult learning - and built the questionnaire so that it provides an exact representation of the construct.

The subjects of the study were 64 adults, participants in post-graduate psycho-pedagogical training (level II, master). There were 43 women and 21 men. The minimum age of the respondents is 28 and the maximum age is 56 (Table 1). Study areas of the participants presented in Table 2.

Table 1: The sample used in the research

\begin{tabular}{ccccc}
\hline Age interval & $20-30$ & $31-40$ & $41-50$ & $51-60$ \\
& years old & years old & years old & years old \\
\hline Women & $8(18.60 \%)$ & $19(44.19 \%)$ & $14(32.56 \%)$ & $2(4.65 \%)$ \\
Men & $7(33.33 \%)$ & $5(23.81 \%)$ & $8(38.10 \%)$ & $1(4.76 \%)$ \\
\hline
\end{tabular}

Table 2: The distribution of learners by undergraduate area

\begin{tabular}{ccccccc}
\hline $\begin{array}{c}\text { Undergraduate } \\
\text { area }\end{array}$ & $\begin{array}{c}\text { Maths and } \\
\text { natural } \\
\text { science }\end{array}$ & Engineering & $\begin{array}{c}\text { Biological } \\
\text { and } \\
\text { biomedical } \\
\text { sciences }\end{array}$ & $\begin{array}{c}\text { Social } \\
\text { science }\end{array}$ & $\begin{array}{c}\text { Humanistic } \\
\text { science and } \\
\text { Arts }\end{array}$ & $\begin{array}{c}\text { Physical } \\
\text { education } \\
\text { and sports }\end{array}$ \\
\hline $\begin{array}{c}\text { No. of learners } \\
\text { (percentage from } \\
\text { the total number) }\end{array}$ & $\begin{array}{c}16 \\
(25 \%)\end{array}$ & $\begin{array}{c}(10.63 \%) \\
(10.94 \%)\end{array}$ & $\begin{array}{c}7 \\
(14.06 \%)\end{array}$ & $\begin{array}{c}(26.56 \%) \\
(7.81 \%)\end{array}$ \\
\hline
\end{tabular}

The purpose of the investigation is to identify the underlying reasons for lifelong learning. The objectives we have targeted are as follows:

O1: Delimitation of the conceptual framework specific to the theme;

$\mathrm{O} 2$ : Identification of some theories and models of adult learning;

O3: Presentation of constitutive aspects of the structure of adult motivation;

O4: Design and implementation of a questionnaire to establish the motivation of adult learning;

O5: Drawing up conclusions based on the interpretation of the results obtained from the application of the questionnaire.

The hypothesis that we started from is that there is a wide range of reasons that make adults learn and that it is necessary to know them exactly when designing and developing the educational programs they are involved in.

Being of an observational type, our research takes into account the types of validity: content (internal), predictive (external), and of construct (consistency). As a research tool, we used the questionnaire, the set of indicators to explore the learning motivation of adult learners including: the intensity of the learning needs (high, moderate, low), the preferred forms of learning (library work, courses, exchange of experience, e-learning etc.), the aspects of the motivational structure involved in learning (needs, motives, interests, beliefs, ideals and conception of the world and life), forms of motivation (positive or negative, intrinsic or extrinsic, cognitive or affective). Based on these indicators, we have formulated suggestive questions to find out about the learning motivation of adult learners. 
Thus the questionnaire contains the following items:

1 . Why did you sign up for this training program?

2. How do you learn best?
a) Individually
b) In groups, teams, etc.

3. What learning methods do you prefer?
a) Study in the library or at home b) Continuous training courses
c) Experience exchanges at work

4. You feel the need to learn:
a) Always
b) Quite often
c) Sometimes
d) Never

5. Do you regard e-learning as an effective form of lifelong learning?
a) Yes
b) No
c) I do not know

6. What do you want to get at the end of this training program?
a) Financial advantages
b) Job safety
c) Professional development
d) Appreciation from the others
e) Comfort
f) Others.

In interpreting the answers to these questions we also took into account the data recorded during the course of the psycho-pedagogical training program, aspects observed after acknowledging the relationship between the students and the discussions they had during the training activities.

\section{Results}

Item 1 is an open question, to which the learners responded differently, depending on their needs and personal reasons. From the point of view of the percentage, the following results were recorded: biological needs, physiological needs $-6.25 \%$, security needs $-14.06 \%$, affiliation needs, cooperation and group membership $-29.69 \%$, esteem and status needs $-21.87 \%$, needs for self-accomplishment $-28.13 \%$.

Closed question, item 2 calls for a choice between two variants. The statistics show the following results: 44 individually and 20 in collectivity.

In item 3 there were identified the learning ways preferred by the learners. Thus, 9 of them said they preferred to learn at home or in a library, 34 chose continuous training, and 21 considered experience exchanges at work as the main learning factor.

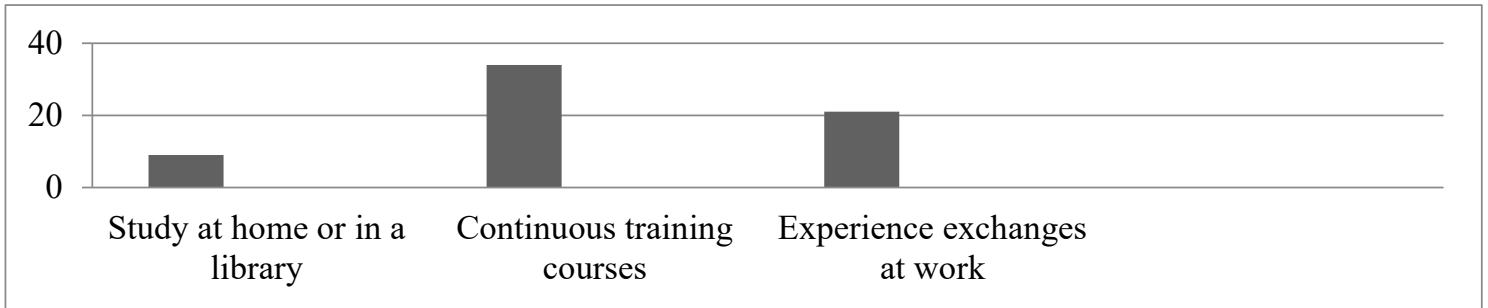

Figure 1. Preferred Learning Ways

Item 4 addresses the intensity of the learning needs. We are interested in the extent to which learners feel the need to learn, and scaling allows us to easily record the given answers.

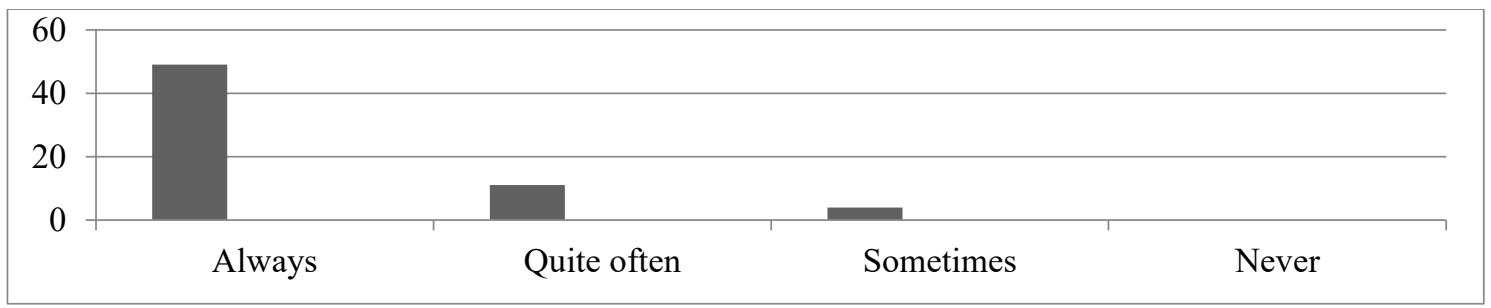

Figure 2. The need to learn 
Because e-learning involves a certain type of motivation, we have been interested in finding out how adult learners are positioned in relation to this aspect. Thus, 42 of them $(65.63 \%)$ do not know enough or do not know about the role of e-learning at all. Only 13 (20.31\%) consider eLearning to be an effective form of lifelong learning.

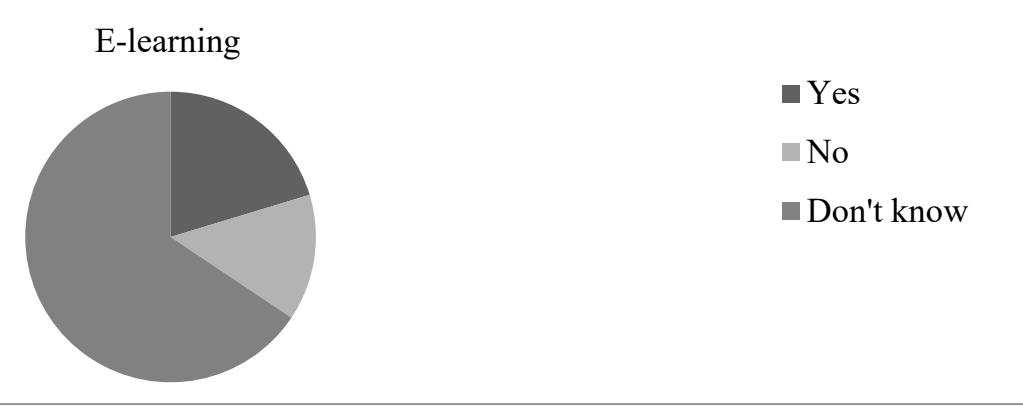

Figure 3. The attitudes of adult learners towards e-learning

Item 6 is a question with an open answer through which we wanted to find out the categories of needs that predominate in adulthood.

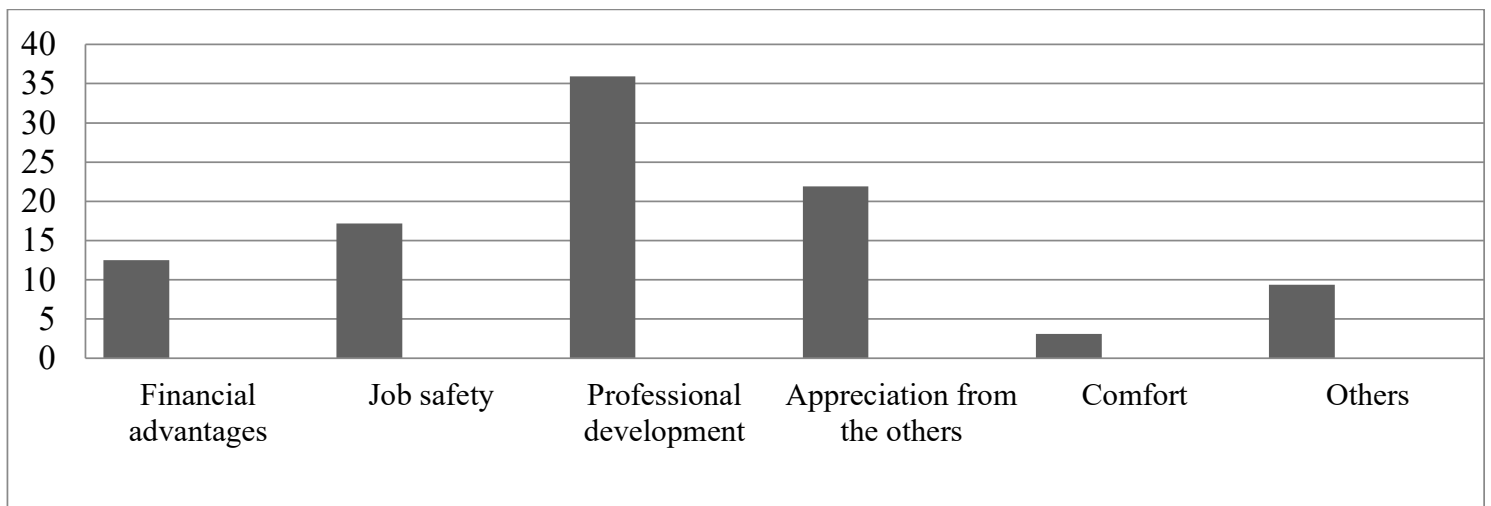

Figure 4. Dominant requirements

Regarding the learning needs mentioned in the last item, we observe the existence of various answers, with a large number of students choosing variants three and four as the answer, namely the professional development (35.94\%) and the appreciation from the others $(21.88 \%)$.

\section{Discussions}

From the analysis of the answers given in the first item we can see the need of the learners to belong to a group, collaboration and interpersonal communication (29.69\%). From the content's point of view, the answers were: "It gives me better communication with my colleagues," "It helps me get along with the others," "It raises me in the eyes of the others." With a similarly similar percentage $(28.13 \%)$, the need for self-accomplishment occupies a high place in the choices of adult learners. The content of the answers refers to: personal and career development, the possibility of promotion, the contact with academic values.

From the analysis of the answers given in item 2 we can see that the majority of adult learners in our sample prefer to learn individually $(59.38 \%)$. Correspondingly interpreted, the answers given to these two items seem contradictory, but there are two factors: preference and efficiency in learning. Although they prefer group activities, adults say they learn better individually. Collaborative learning is important, but we find that the level of autonomy, independence in learning is high. That is why self-directed learning needs to be better exploited at this age. 
We observe that most of the respondents (53.13\%) chose continuous training courses, which can be a factor of motivation, support and stimulation of adult learning. Experience sharing at work takes the second place (32.81\%), which points to the role of partnerships, to learning from the experience of others, collaborative learning that is so necessary in generating new ideas and in energetic support.

The high number of learners $(76.56 \%)$ who consider the need for learning to be permanent justifies our saying that the problem of learning in adulthood is based on a strong motivation of an intrinsic nature.

We find an imbalance between the number of adult learners who can decide on the role of elearning and the number of those who do not have enough information or do not know exactly what the e-learning role is in the present society. Item 5 is related to the role of "e-motivation", which involves the knowledge and use of information technologies as a modern way of learning in adults. With its intrinsic motivation, "e-motivation" has positive effects on learning, and this thing is is not understood and, therefore, not yet capitalized.

The analysis of the answers given in item 6 suggests that there is need for self-accomplishment, cooperation and belonging to the group. Their presence in a percentage of 50\% (namely $57.82 \%$ ) is due, we believe, to the high level of training of adult learners with whom we work. It is important to analyze whether this percentage is also reached for other socio-professional categories or when applying the questionnaire in another context or socio-cultural environment.

Pedagogical literature offers a number of suggestions on the importance of learning and personal development (eg Mitkovska, 2009; Maurer, 2001). The results of our other research have shown that the previously mentioned needs occupy an important place in the respondents' choices. For example, in a study on student motivation, that took place in the academic year 2018-2019 on a sample of 43 students enrolled in the Psycho-pedagogic Module (Master, 2nd year), we obtained similar answers to item 6. Students who do not work - $11(25.58 \%)$ - wrote down the financial advantages firstly and those who have a job - $32(74.42 \%)$ chose the professional development variant. We also obtained similar results in this item in a study on motivation carried out in 2019 on a sample of people working with children from disadvantaged backgrounds (Center for Inclusive Education, Băbeni, and Gymnasium Secondary School, Râmnicu Vâlcea, Romania) . Out of the total of 93 respondents, 39 (41.94\%) were focused on professional development and $32(34.41 \%)$ on the appreciations of the others. The rest of the answers - $22(23.65 \%)$ represent other choices.

\section{Conclusion}

Adult education is an important factor in the democratization of social life and a means of exercising the right to education of each individual. Adult learning can become thriving only if the adult individual reaches a certain level of maturity and self-efficacy, becomes self-directed and motivated to accomplish the tasks he has to complete, recognizes his roles and responsibilities in society, realizes that what he learns contributes to his welfare and to the community he belongs to. It is observed that in adult age the learners have as a main reason to participate the need to improve their informational content (in order to exercise their profession or occupation) and professional re-profiling (professional reconversion). The reasons why adults are involved in learning actions organized by specialized institutions have been the subject of many specialized studies. Among the most important are: the desire to climb on the professional scale, the personal interest in a particular subject, the maintenance of social relationships or the job, the desire to support others or the personal interest. 
Although the motivations to participate in continuous training courses are often related to work, the participation to learning is a direct result of special life situations in which participation in learning has been seen as a solution or means of changing or solving a problem or dilemma in life. Regardless of reasons, interests or needs, lifelong learning remains a necessity, a condition of adapting to social dynamics, which is becoming more and more complex.

We recommend referring to the real motivations of adults in the learning, designing and developing process of the educational programs in which they are involved according to their needs and interests.

\section{References}

Allport, G. W. (1961). Pattern and Gowth in Personality. New York: Holt, Rinehart and Winston.

Becker, G. S. (1993). Human Capital. A Theoretical and Empirical Analysis, with Special Reference to Education. 3rd Edition, Chicago: University of Chicago Press.

Boshier, R. W., \& Collins, J. B. (1985). The Houle typology after twenty-two years: A large-scale empirical test. Adult Education, 35(2), 113-130. doi: 10.1177.0001848185035003001

Brookfield, S. D. (1986). Understanding and facilitating adult learning. San Francisco: JosseyBass.

Cross, K. P. (1981). Adults as Learners. Increasing Participation and Facilitating Learning. San Francisco: Jossey-Bass.

Darkenwald, G. G., \& Merriam, S. B. (1982). Adult Education. Foundations of practice. New York: Harper and Row.

European Commission (2001). Commission of the European Communities. Making a European Area of Lifelong Learning a Reality. Retrived January 26, 2019, from http://viaa.gov.lv/files/free/48/748/pol_10_com_en.pdf

European Commission (2006). Communication from the Commission. Adult learning: It is never too late to learn, COM 614, 23.10.2006. Retrived December 13, 2019, from https://eurlex.europa.eu/LexUriServ/LexUriServ.do?uri=COM:2006:0614:FIN:EN:PDF

Fishbein, M., \& Ajzen, I. (1975). Belief, attitude, intention and behavior: An introduction to theory and research. Reading, MA: Addison Wesley.

Hiemstra, R., \& Sisco, B. (1990). Individualizing instruction: Making learning personal, empowering, and successful. San Francisco: Jossey-Bass.

Houle, C.O. (1961). The inquiring mind. Madison. WI: University of Wisconsin Press.

Jarvis, P. (1987). Adult learning in the social context. Volume 78, London and New York: Routledge. Taylor \& Francis Group.

Jarvis, P., \& Wilson, A. L. (2002). International dictionary of adult and continuing education (Rev. ed.). London: Kogan Page.

Kidd, J. R. (1973). How adults learn. New York: Association Press.

Knowles, M. S. (1970). The modern practice of adult education: Andragogy versus pedagogy. New York: Association Press.

Knowles, M. S., \& Associates (1984). Andragogy in action: Applying modern principles of adult learning. San Francisco: Jossey-Bass.

Knowles, M. S., Holton, E. F. \& Swanson, R. A. (2012). The adult learner. The Definitive Classic in Adult Education and Human Resource Development. Seventh Edition, London and New York: Routledge. Taylor \& Francis Group.

Knox, A. B. (1977). Adult development and learning. San Francisco: Jossey-Bass.

Kocayörük, E. (2010). Pathways to Emotional Well-Being and Adjustment in Adolescence: The Role of Parent Attachment and Competence. International Online Journal of Educational Sciences, 2(3), 719-737. Retrieved June 27, 2019, from http:// https://www.researchgate.net/publication/49591625_Pathways_to_Emotional_WellBeing_and_Adjustment_in_Adolescence_The_Role_of_Parent_Attachment_and_Compet ence 
Kocayörük, E., Altıntaş, E., Şimşek, Ö. F., Bozanoğlu, İ., \& Çelik, B. (2018). Ontological wellbeing of university students: A cluster-analysis approach. Hacettepe University Journal of Education, 33(3), 550- 564. doi: 10.16986/HUJE.2017032927

Kolb, D. A. (1984). Experiential learning: Experience as the source of learning and development. New Jersey: Prentice Hall.

Mahler, F. (1983). Introduction to Juventology. București: Scientific and Encyclopaedic Publishing House.

Maslow, A. (1970). Motivation and Personality. New York: Harper \& Row.

Merriam, M. S., \& Caffarela, R. (1991). Learning in Adulthood. A comprehensive guide. San Francisco: Jossey-Bass.

Mezirow, J. (1978a). Education for perspective transformation: Women's re-entry programs in community colleges. New York: Teacher's College, Columbia University.

Mezirow, J. (1978b). Perspective transformation. Adult Education, 28, 100-110. doi: $10.1177 / 074171367802800202$

Mezirow, J. (2000). Learning to Think Like an Adult. Core Concepts of Transformation Theory. In J. Mezirow et al. (Eds.), Learning as Transformation. Critical Perspectives on a Theory in Progress (pp. 3-33). San Francisco: Jossey-Bass.

Mitkovska, S. J. (2010). The need of continuous professional teacher development. Procedia Social and Behavioral Sciences. 2(2), 2921-2926.

OECD (1973). Recurrent Education: A strategy for Lifelong Learning. Paris: Organization for Economic Cooperation and Development.

Price, F., \& Kadi-Hanifi, K. (2011). E-motivation! The role of popular technology in student motivation and retention. Research in Post-Compulsory Education, 16(2), 173-187. doi: 10.1080/13596748.2011.575278

Rubenson, K. (1977). Participation in recurrent education: A research review. Paris: Center for Educational Research and Innovation Organization for Economic Cooperation and Development.

Ryan, R. M., \& Deci, E. L. (2000). Self-determination theory and the facilitation of intrinsic motivation, social development and well-being. American Psychologist, 55(1), 68-78. doi: 10.1037110003-066X.55.1.68

Sălăvăstru, D. (2004). The psychology of education, Iași: Polirom Publishing House.

Sillamy, N. (1996). Dictionary of psychology. București: Univers Enciclopedic Publishing House.

Maurer, T. J. (2001). Carrer-relevant learning and development, worker age, and beliefs about self-efficacy for development, Retrived January 24, 2019, from https://doi.org/10.1177/014920630102700201

Tough, A. (1971). The Adult's Learning Projects. A Fresh Approach to Theory and Practice in Adult Learning. Austin, Texas: Learning Concepts.

UNESCO (1979). Resolutions. Records of the General Conference Twentieth Session. Twentieth Session, Volume 1. Retrived February 7, 2019, from http://ulis2.unesco.org/images/0011/001140/114032EO.pdf

Urbańczyk, F. (1975). Didactics for adults, București: EDP.

Wlodkowski, R. J. (1989). Instructional design and learner motivation. In K. A. Johnson \& L. J. Foa (Eds.), Instructional design: New alternatives for effective education and training (pp. 47-60). New York: McMillan. 